\title{
Water Optics and Water Colour Remote Sensing
}

\author{
Yunlin Zhang ${ }^{1, *}$ (D), Claudia Giardino ${ }^{2}$ and Linhai $\mathrm{Li}^{3}$ \\ 1 Taihu Laboratory for Lake Ecosystem Research, State Key Laboratory of Lake Science and Environment, \\ Nanjing Institute of Geography and Limnology, Chinese Academy of Sciences, Nanjing 210008, China \\ 2 Institute for Electromagnetic Sensing of the Environment, National Research Council of Italy, via Bassini 15, \\ 20133 Milan, Italy; giardino.c@irea.cnr.it \\ 3 Marine Physical Laboratory, Scripps Institution of Oceanography, University of California San Diego, \\ La Jolla, CA 92093, USA; lil032@ucsd.edu \\ * Correspondence: ylzhang@niglas.ac.cn; Tel.: +86-25-8688-2198; Fax: +86-25-5771-4759
}

Academic Editor: Prasad S. Thenkabail

Received: 4 August 2017; Accepted: 7 August 2017; Published: 9 August 2017

\begin{abstract}
The editorial paper aims to highlight the main topics investigated in the Special Issue (SI) "Water Optics and Water Colour Remote Sensing". The outcomes of the 21 papers published in the SI are presented, along with a bibliometric analysis in the same field, namely, water optics and water colour remote sensing. This editorial summarises how the research articles of the SI approach the study of bio-optical properties of aquatic systems, the development of remote sensing algorithms, and the application of time-series satellite data for assessing long-term and temporal-spatial dynamics in inland, coastal, and oceanic waters. The SI shows the progress with a focus on: (1) bio-optical properties (three papers); (2) atmospheric correction and data uncertainties (five papers); (3) remote sensing estimation of chlorophyll- $a$ (Chl- $a$ ) (eight papers); (4) remote sensing estimation of suspended matter and chromophoric dissolved organic matter (CDOM) (four papers); and (5) water quality and water ecology remote sensing (four papers). Overall, the SI presents a variety of applications at the global scale (with case studies in Europe, Asia, South and North America, and the Antarctic), achieved with different remote sensing instruments, such as hyperspectral field and airborne sensors, ocean colour radiometry, geostationary platforms, and the multispectral Landsat and Sentinel-2 satellites. The bibliometric analysis, carried out to include research articles published from 1900 to 2016, indicates that "chlorophyll-a", "ocean colour", "phytoplankton", "SeaWiFS" (Sea-Viewing Wide Field-of-View Sensor), and "chromophoric dissolved organic matter" were the five most frequently used keywords in the field. The SI contents, along with the bibliometric analysis, clearly suggest that remote sensing of Chl- $a$ is one of the topmost investigated subjects in the field.
\end{abstract}

Keywords: water optics; water colour remote sensing; bibliometric analysis; popular study topics; chlorophyll- $a$

\section{Water Optics and Water Colour Remote Sensing from a Bibliometrics Perspective}

Bibliometrics, which was first introduced by Pritchard [1], has been widely used to quantitatively and qualitatively analyse scientific production and research trends at the decade to century scale with a large amount of data [2]. Using the Science Citation Index-Expanded (SCI-Expanded, where SCI is the multidisciplinary database of the Institute for Scientific Information, Philadelphia, PA, USA) database of the Web of Science and "bibliometric analysis" as the topic, 1502 papers could be searched by the end of 2016. The bibliography of all articles related to water optics and water colour remote sensing from 1900 to 2016, was compiled by searching, in the online version of SCI-Expanded, the following keywords: TS (Topic) $=$ ("inherent optical propert *" or "apparent optical propert *" or "bio-optical propert * "or "remote sensing reflectance *" or "absorption coefficient $*$ " or "scattering coefficient $*$ " or 
CDOM) or (("suspended matter *" or "particle matter *" or CDOM or chlorophyll or phycocyanin or "water colour *" or bloom * or macrophyte *) and "remote sensing *")) and TS = (lake* or reservoir * or ocean * or coastal * or estuary * or bay *). Keywords contain the most critical information in most papers whose frequency was used to discover study hotspots. Notably, only author keywords, not KeyWords Plus, were used for this analysis [3,4].

The total publication number was 4809 when the aforementioned search strategy was used. We presented the 20 most frequently used keywords of water optics and water colour remote sensing research (Figure 1). "chlorophyll-a" (Chl-a), "ocean colour", "phytoplankton", "SeaWiFS" (Sea-Viewing Wide Field-of-View Sensor), and "chromophoric dissolved organic matter (CDOM)" were the five most frequently used keywords of the study subject after excluding, for obvious reasons, the keyword "remote sensing". In particular, the frequency of "Chl- $a$ " was as high as 532, which was much higher than the second frequently used keyword "ocean colour" (86). The result of SeaWiFS indicated the role played in the past from this sensor, while for recent years sensors such as Moderate Resolution Imaging Spectroradiometer (MODIS), Medium-Resolution Imaging Spectrometer (MERIS), and OLCI might be considered as improved successors. This result indicated that $\mathrm{Chl}-a$-related study was the popular study topics in the field of water optics and water colour remote sensing.

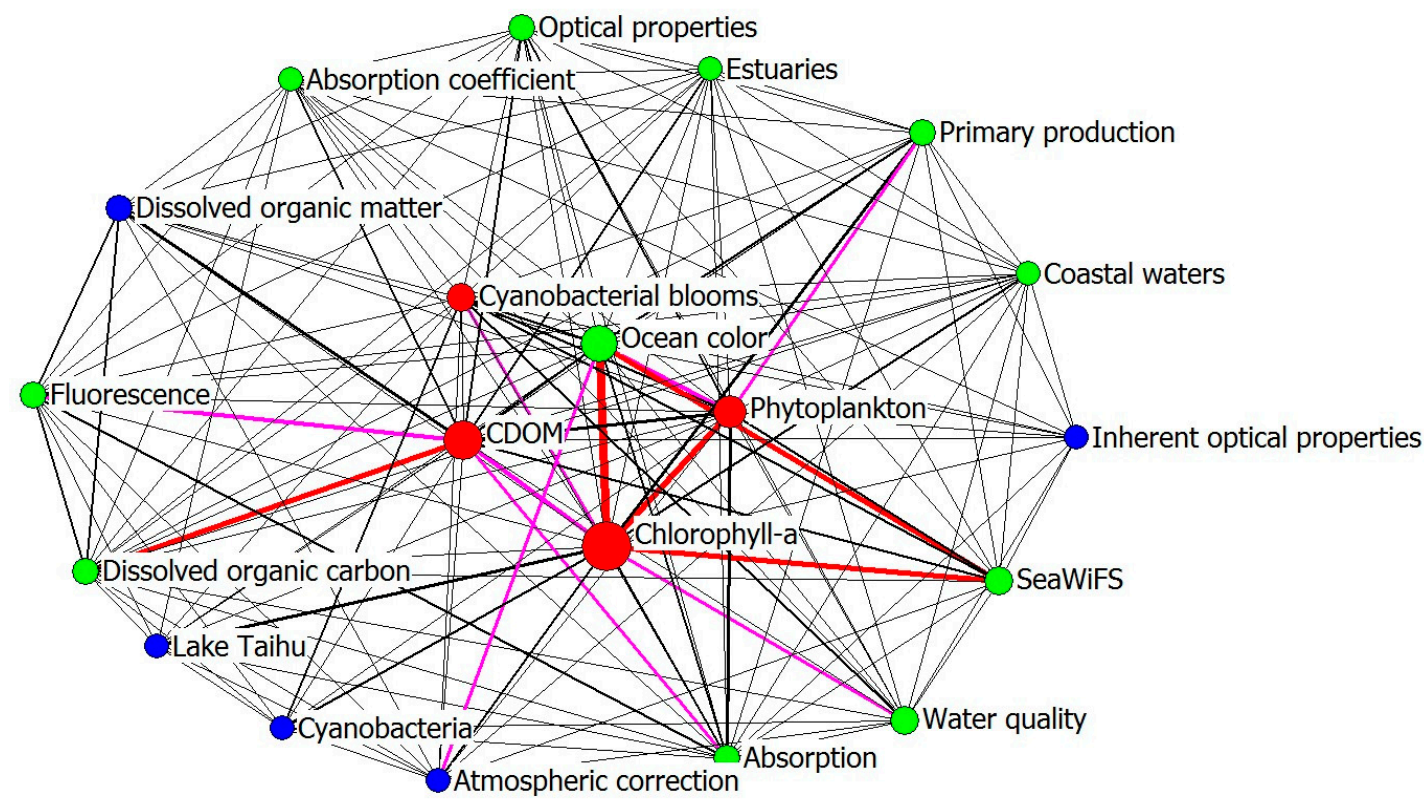

Figure 1. Co-word network of high-frequency keywords in water optics and water colour remote sensing research. The size of lines represents the number of co-occurrences. The colour of lines represents the group of the co-occurrences number: red $\geq 50 ; 25 \leq$ magenta $<50$; black $\leq 25$. The size of nodes represents the keyword frequency; the colour of nodes represents the group of the number of connections to other nodes: red $=20 ; 15 \leq$ green $<20 ; 10 \leq$ blue $<15$.

\section{Overview and Scope of the Special Issue}

Available water resources, including rivers, reservoirs, lakes, coastal waters, and oceans, are emerging as a limiting factor, not only in quantity, but also in quality, for human development and ecological stability. Declining water quality has become a global issue of significant concern as anthropogenic activities expand and climate change threatens to cause major alterations to the hydrological cycle. Thus, monitoring the physical, chemical, and biological status of those waters is immensely important. Remote sensing has the potential to provide an invaluable complementary source of data at local to global scales. However, accurate, cost-effective, frequent, and synoptic retrieval algorithms of in-water optical and biogeochemical parameters, as well as information on the biophysical properties of the monitored waters, have several challenges. 
This Special Issue (SI) focusing on "Water Optics and Water Colour Remote Sensing" is specifically aimed at addressing: (1) issues on water optics including the characterisation of optical properties among rivers, reservoirs, lakes, coastal waters, and open sea, modeling the relationships between apparent optical properties (AOPs) and inherent optical properties (IOPs); and (2) challenges on retrieval algorithm developments, validation, and applications of remote sensing of rivers, reservoirs, lakes, coastal waters, and open ocean. This SI presents many of the recent progresses in this rapidly growing research area.

\section{Highlights of Research Articles}

The main topics of this SI concentrate on: (1) bio-optical properties (three papers); (2) atmospheric correction and data uncertainties (five papers); (3) remote sensing estimation of Chl- $a$ (eight papers); (4) remote sensing estimation of suspended matter and CDOM (four papers); and (5) remote sensing estimation of other water qualities and water ecological parameters (four papers). Overall, Chl- $a$ estimation-related study is a major topic in this SI, which is consistent to the previously described bibliometrics analysis.

There are three papers on bio-optical properties in this issue. Ma et al. [5] reported the spatial distribution of the diffuse attenuation coefficient of photosynthetic active radiation (PAR) $\left(K_{d}(P A R)\right)$ and its main regulating factors in 26 lakes and reservoirs in Northeast China. The results showed that total suspended matter was the dominant factor in determining $K_{\mathrm{d}}(\mathrm{PAR})$ values and best correlated with $K_{d}(\mathrm{PAR})$. Zhou et al. [6] presented a model to describe the polarisation patterns of celestial light, when refracted by wavy water surfaces. Scattering skylight dominates the polarisation patterns, while direct solar light is the dominant source of the intensity of the underwater light field. Wind speed has an influence on disturbing the patterns under water. To optimise atmospheric correction and bio-optical algorithms for the wide variety of lake optical conditions, Eleveld et al. [7] proposed two water type classification schemes through a cluster analysis of in situ hyperspectral remote sensing reflectance spectra collected around the world.

There are five papers on atmospheric correction and data uncertainties in this issue. In each of the three atmospheric correction papers, one or more atmospheric correction strategies were evaluated. The commercial ATCOR4 code was applied to airborne imagery [8], a series three of methods (i.e., ACOLITE NIR, ACOLITE SWIR, and MACCS) based on the use of short-wave infrared (SWIR) spectral bands was applied to satellite data of turbid coastal waters [9], and again three atmospheric correction methods (ACOLITE, 6SV, and Sen2Cor) were applied to Sentinel-2 images of lakes [10]. Two data uncertainties papers discussed the impact of the Signal-to-Noise Ratio of sensor design on the Chl- $a$ and total suspended matter algorithms in four lakes located at Mamirauá Sustainable Development Reserve (Amazonia, Brazil) [11], and sensors selection, near-coincident data determination, and potential limitations of remote sensing measurements for surface and near-surface conditions [12].

There are eight papers on the remote sensing estimation of Chl- $a$ in this issue. These papers presented Chl- $a$ remote sensing estimation models including the height of the 810 peak of remote sensing reflectance [13], the comparison of four empirical models (Blue-Green Ratio Model, Two-Band NIR-Red Ratio Model, Three-Band NIR-Red Model, and Four-Band NIR-Red Model) [14], a coupled atmosphere-hydro-optical model [15], the combination of AisaFENIX sensor and ATCOR4 in image-driven parametrisation [8], iterative stepwise elimination partial least squares regression based on field hyperspectral [16], and an improved baseline fluorescence approach [17]. In addition, long-term spatial and temporal variabilities of Chl- $a$ from MODIS and SeaWiFS observations in the Bohai Sea (2000-2012) [18] as well as from MERIS images in Lake Erie (2004-2012) [19] were elucidated.

There are five papers on the remote sensing estimation of suspended matter and CDOM in this issue. Kutser et al. [13] found that the height of the 810 peak was in good correlation with suspended matter and assessed the application of this finding on Landsat 8 and Sentinel-2 images. Wang et al. [20] developed an algorithm using the slope of $R_{\mathrm{rs}}(490)$ and $R_{\mathrm{rs}}(555)$ to estimate particle cross-sectional area concentration from the Geostationary Ocean Colour Imager (GOCI). An iterative stepwise elimination 
partial least squares regression based on field hyperspectral was used to estimate water total suspended matter concentration in irrigation ponds in Japan [16]. Campanelli et al. [21] developed an empirical band ratio model using $R_{\mathrm{rs}}(667) / R_{\mathrm{rs}}(488)$ to estimate CDOM using MODIS ocean colour sensor images and data collected on the North-Central Western Adriatic Sea (Mediterranean Sea).

Lastly, there are four papers on the remote sensing estimation of other water qualities and water ecological parameters in this issue. Turbidity climatology over an eight-year period (2004-2011) in Apalachicola Bay was investigated based on remote sensing estimation from Landsat $5 \mathrm{TM}$ and Landsat 8 OLI imagery using a single-band empirical relationship of band 3 [22]. Deng et al. [23] tested the applicability of the Vertically Generalised Production Model (VGPM) to estimate phytoplankton primary production by comparing the model-derived and the in situ results, investigated the long-term temporal-spatial variations in primary production using MODIS data, and further discussed the potential affecting factors in Lake Taihu. Liang et al. [24] developed a new cyanobacteria and macrophytes index (CMI) based on a blue, a green, and a shortwave infrared band to separate waters with cyanobacterial scums from those dominated by aquatic macrophytes. Deng et al. [25] employed 1375 seasonally continuous Landsat TM/ETM+/OLI data scenes to evaluate the lake water area changes from 1987 to 2015, and found a loss of $241.39 \mathrm{~km}^{2}$ (10.67\%) from 1987-2002 to 2005-2015 in Wuhan Urban Agglomeration, China.

\section{Conclusions}

This SI presents the state-of-the-art and represents the progress in the field of "Water Optics and Water Colour Remote Sensing". The 21 papers published in this SI present a variety of studies mainly related to bio-optical properties measurement and modeling, atmospheric correction and data uncertainties, remote sensing algorithms for Chl- $a$, suspended matter and CDOM, as well as water quality and water ecology applications. The SI covers a variety of applications at the global scale (with case studies in Europe, Asia, South and North America, and even the Antarctic), with different remote sensing instruments, ranging from hyperspectral field and airborne sensors, to ocean colour radiometry, geostationary platforms, and multispectral sensors such as Landsat and Sentinel-2. In particular, both the bibliometric analysis and a major number of articles in the SI suggest a popular and important research topic in the field-remote sensing of Chl- $a$, a parameter with a global relevance (phytoplankton is a prolific primary producer occurring in oceans and the world's freshwater sources) and one of primary interest for water quality authorities.

Acknowledgments: This study was jointly funded by the National Natural Science Foundation of China (grant 41325001), the Key Program of the Chinese Academy of Sciences (ZDRW-ZS-2017-3-4), and the Key Research Program of Frontier Sciences of the Chinese Academy of Sciences (QYZDB-SSW-DQC016). We would like to thank the staff in the editorial office and all the authors who contribute to the special issue.

Conflicts of Interest: The authors declare no conflict of interest.

\section{References}

1. Pritchard, A. Statistical bibliography or bibliometrics? J. Doc. 1969, 25, 348-349.

2. Zhi, W.; Yuan, L.; Ji, G.; Liu, Y.; Cai, Z.; Chen, X. A bibliometric review on carbon cycling research during 1993-2013. Environ. Earth Sci. 2015, 74, 6065-6075. [CrossRef]

3. Ho, Y.S.; Siu, E.; Chuang, K.Y. A bibliometric analysis of dengue-related publications in the science citation index expanded. Future Virol. 2016, 11, 631-648. [CrossRef]

4. Zhang, Y.; Yao, X.; Qin, B. A critical review of the development, current hotspots, and future directions of lake taihu research from the bibliometrics perspective. Environ. Sci. Pollut. Res. 2016, 23, 12811-12821. [CrossRef] [PubMed]

5. Ma, J.; Song, K.; Wen, Z.; Zhao, Y.; Shang, Y.; Fang, C.; Du, J. Spatial distribution of diffuse attenuation of photosynthetic active radiation and its main regulating factors in inland waters of northeast China. Remote Sens. 2016, 8, 964. [CrossRef] 
6. Zhou, G.; Wang, J.; Xu, W.; Zhang, K.; Ma, Z. Polarization patterns of transmitted celestial light under wavy water surfaces. Remote Sens. 2017, 9, 324. [CrossRef]

7. Eleveld, M.A.; Ruescas, A.B.; Hommersom, A.; Moore, T.S.; Peters, S.W.M.; Brockmann, C. An optical classification tool for global lake waters. Remote Sens. 2017, 9, 420. [CrossRef]

8. Markelin, L.; Simis, S.; Hunter, P.; Spyrakos, E.; Tyler, A.; Clewley, D.; Groom, S. Atmospheric correction performance of hyperspectral airborne imagery over a small eutrophic lake under changing cloud cover. Remote Sens. 2017, 9, 2. [CrossRef]

9. Novoa, S. Atmospheric corrections and multi-conditional algorithm for multi-sensor remote sensing of suspended particulate matter in low-to-high turbidity levels coastal waters. Remote Sens. 2017, 9, 61. [CrossRef]

10. Martins, V.S.; Barbosa, C.C.F.; de Carvalho, L.A.S.; Jorge, D.S.F.; Lobo, F.d.L.; Novo, E.M.L.d.M. Assessment of atmospheric correction methods for sentinel-2 msi images applied to amazon floodplain lakes. Remote Sens. 2017, 9, 322. [CrossRef]

11. Jorge, D.; Barbosa, C.; Carvalho, L.S.D.; Affonso, A.; Lobo, F.; Novo, E. Snr (signal-to-noise ratio) impact on water constituent retrieval from simulated images of optically complex amazon lakes. Remote Sens. 2017, 9, 644. [CrossRef]

12. Hansen, C.H.; Burian, S.J.; Dennison, P.E.; Williams, G.P. Spatiotemporal variability of lake water quality in the context of remote sensing models. Remote Sens. 2017, 9, 409. [CrossRef]

13. Kutser, T.; Paavel, B.; Verpoorter, C.; Ligi, M.; Soomets, T.; Toming, K.; Casal, G. Remote sensing of black lakes and using $810 \mathrm{~nm}$ reflectance peak for retrieving water quality parameters of optically complex waters. Remote Sens. 2016, 8, 497. [CrossRef]

14. Lins, R.C.; Martinez, J.M.; Marques, D.D.M.; Cirilo, J.A.; Fragoso, C.R., Jr. Assessment of chlorophyll- $a$ remote sensing algorithms in a productive tropical estuarine-lagoon system. Remote Sens. 2017, 9, 516. [CrossRef]

15. Arabi, B.; Salama, M.S.; Wernand, M.R.; Verhoef, W. Mod2sea: A coupled atmosphere-hydro-optical model for the retrieval of chlorophyll- $a$ from remote sensing observations in complex turbid waters. Remote Sens. 2016, 8, 722. [CrossRef]

16. Wang, Z.; Kawamura, K.; Sakuno, Y.; Fan, X.; Gong, Z.; Lim, J. Retrieval of chlorophyll- $a$ and total suspended solids using iterative stepwise elimination partial least squares (ise-pls) regression based on field hyperspectral measurements in irrigation ponds in higashihiroshima, Japan. Remote Sens. 2017, 9, 264. [CrossRef]

17. Zeng, C.; Zeng, T.; Fischer, A.; Xu, H. Fluorescence-based approach to estimate the chlorophyll- $a$ concentration of a phytoplankton bloom in ardley cove (Antarctica). Remote Sens. 2017, 9, 210. [CrossRef]

18. Zhang, H.; Qiu, Z.; Sun, D.; Wang, S.; He, Y. Seasonal and interannual variability of satellite-derived chlorophyll-a (2000-2012) in the bohai sea, china. Remote Sens. 2017, 9, 582. [CrossRef]

19. Zolfaghari, K.; Duguay, C. Estimation of water quality parameters in lake erie from meris using linear mixed effect models. Remote Sens. 2016, 8, 473. [CrossRef]

20. Wang, S.; Yu, H.; Qiu, Z.; Sun, D.; Zhang, H.; Zheng, L.; Xiao, C. Remote sensing of particle cross-sectional area in the bohai sea and yellow sea: Algorithm development and application implications. Remote Sens. 2016, 8, 841. [CrossRef]

21. Campanelli, A.; Pascucci, S.; Betti, M.; Grilli, F.; Marini, M.; Pignatti, S.; Guicciardi, S. An empirical ocean colour algorithm for estimating the contribution of coloured dissolved organic matter in north-central western adriatic sea. Remote Sens. 2017, 9, 180. [CrossRef]

22. Joshi, I.D.; D'Sa, E.J.; Osburn, C.L.; Bianchi, T.S. Turbidity in apalachicola bay, florida from landsat 5 TM and field data: Seasonal patterns and response to extreme events. Remote Sens. 2017, 9, 367. [CrossRef]

23. Deng, Y.; Zhang, Y.; Li, D.; Shi, K.; Zhang, Y. Temporal and spatial dynamics of phytoplankton primary production in lake taihu derived from modis data. Remote Sens. 2017, 9, 195. [CrossRef]

24. Liang, Q.; Zhang, Y.; Ma, R.; Loiselle, S.; Li, J.; Hu, M. A modis-based novel method to distinguish surface cyanobacterial scums and aquatic macrophytes in lake taihu. Remote Sens. 2017, 9, 133. [CrossRef]

25. Deng, Y.; Jiang, W.; Tang, Z.; Li, J.; Lv, J.; Chen, Z.; Jia, K. Spatio-temporal change of lake water extent in wuhan urban agglomeration based on landsat images from 1987 to 2015. Remote Sens. 2017, 9, 270. [CrossRef]

(C) 2017 by the authors. Licensee MDPI, Basel, Switzerland. This article is an open access article distributed under the terms and conditions of the Creative Commons Attribution (CC BY) license (http:/ / creativecommons.org/licenses/by/4.0/). 